\title{
Spatial Layout, Orientation Relative to the Observer, and Perceived Projection in Pictures Viewed at an Angle
}

\author{
E. Bruce Goldstein \\ University of Pittsburgh
}

\begin{abstract}
Judgments of the spatial layout of a three-dimensional array of pictured dowels remain relatively constant as viewing angle changes, whereas judgments of their orientation relative to the observer (perceived orientation) vary These changes in perceived orientation as viewing angle changes, called the differential rotation effect (DRE), also occur for stımulı such as the eyes in portraits, which are not extended in pictorial space Thus, the mechanism for the DRE does not depend on the extension of pictured objects in depth The DRE is decreased when back-illuminated pictures are viewed in the dark so that the picture plane is not visible This result suggests that the DRE depends on information that defines a pictured object's direction relative to the picture plane The difference in the way spatial layout and perceived orientation are affected by changes in viewing angle suggests that it is important to distınguish between these two attributes of pictures In addition, another attribute, the picture's projection, should be distinguished from spatial layout and perceived orientation When these distinctions are not made, the result is confusion, particularly when discussing whether or not pictures viewed at an angle appear distorted
\end{abstract}

A scene depicted in linear perspective and viewed from the correct station point can, by duplicatıng the geometrical array of the original scene, create a perception similar to the perception of the original scene Many investigators have noted, however, that changing the geometrical array by viewing a picture from an incorrect station point does not cause a corresponding distortion in the observer's perception of the picture (Haber, 1980, Pirenne, 1970; Rosinskı \& Farber, 1980). This contention, however, is only partially correct. One attribute of pictures, the spatial layout of objects in the picture, does remain relatively constant with changes in viewing angle; however, another attribute, the orientation in which pictured objects point relative to the observer, is far from constant with changes in viewing angle (Goldstein, 1979).

These findings pose a potential paradox. On one hand, the orientations of pictured objects relative to the observer change as an observer's viewing angle changes, while on the other hand, the perceived spatial layout of these objects remains relatively constant One purpose of the present article is to investigate this paradox in more detall by having observers make both orientat1on-relative-to-the-observer and spatial layout judgments on a picture of known spatial layout so that these two attributes can be compared with each other and with the actual spatial layout. Observers viewed a picture of a triangular arrangement of vert1cal dowels at different viewing angles and judged both the spatial layout of these dowels (Experiment 1) and the orientations of

I wish to thank Sam Chol, Ang Franzetta, and Paul Haber for running subjects for some of the experiments I also thank Frank Valentich for building the apparatus

I regret that reprints are not avarlable

Correspondence concerning this article should be addressed to $\mathrm{E}$ Bruce Goldsteın, Department of Psychology, University of Pittsburgh, Pittsburgh, Pennsylvania 15260 pairs of dowels relative to the observer (Experıment 2) (For brevity, orientation relative to the observer will be referred to as percelved ortentation)

Following these two experıments, I will look more closely at possible mechanisms responsible for orientation perception by askıng how perceived orientation is affected by (a) the extension of pictured objects in pictorial space (Experiments 3 and 4) and by (b) visibility of the picture plane (Experıment 5).

\section{Experiment 1}

In this experiment, a person's ability to reproduce a picture's spatial layout is measured by having observers judge the locations of three vertical dowels arranged in a triangular layout when a picture of these dowels is viewed from different angles.

\section{Method}

Observers Five undergraduates at the University of Pittsburgh who were nave to the purpose of this experiment were observers

Stimulus A line drawing of the picture used in these experiments is shown in Figure 1 The actual stımulus, which did not include the letters shown in the figure, was a $4 \times 5$-in $(102 \times 127 \mathrm{~cm})$ black and white photograph of three dowels on a homogeneous white surface, in front of a homogeneous white background The dowels were painted with black-and-white horizontal stripes to make them easy to differentiate from the ground plane and from the background The 3 375-in (8 572 $\mathrm{cm})$ high dowels, when photographed from a distance of 46 in (11684 $\mathrm{cm})$, resulted in an image 1125 in $(286 \mathrm{~cm})$ high in the photograph

Procedure Observers viewed the picture monocularly from a distance of $15 \mathrm{in}(381 \mathrm{~cm})$, with head fixed in position by a chin rest The picture was placed on a plane that was rotated to present the picture at viewing angles of $20^{\circ}, 45^{\circ}, 70^{\circ}, 90^{\circ}, 110^{\circ}, 135^{\circ}$, and $160^{\circ}$, with viewng angles presented in random order Vlewing angle is defined as the angle between the picture plane and the observer's line of sight when looking straight ahead $A$ viewing angle of $0^{\circ}$ means that the picture plane is parallel to the observer's line of sight, with the right edge of the picture 
closest to the observer A viewing angle of $90^{\circ}$ means that the picture plane is perpendicular to the observer's line of sight, and a viewing angle of $180^{\circ}$ means that the picture plane is parallel to the observer's line of sight, with the left edge of the picture closest to the observer (See Figure 2 of Goldstein, 1979, for further detals )

Because binocular viewing results in two different viewing angles, one for each eye, the pictures in this and all subsequent experiments were viewed monocularly, with the line of sight intersecting the picture's center of rotation Monocular viewing made unambiguous determination of viewing angle possible Pilot experiments, in which monocular and binocular viewing were compared, showed that results were identical for both viewing conditions

Pictures were continuously on view so that observers could see the pictures as they were rotating to each new viewing angle The constant visibility of the pictures, the visibility of the edges of both the picture and the rotating plane on which they were displayed, and the contrast between the black plane on which the pictures were displayed, and the white border of the picture made the viewing angle and changes in viewing angle obvious to the observer

As the observers viewed the picture from each angle, they judged the spatial layout of the dowels by arranging three dises on a piece of $81 / 2 \times$ 11 -in $(2159 \times 2797 \mathrm{~cm})$ paper to duplicate the positions of the bases of the dowels in the picture The edges of the paper on which the observers arranged the discs were clearly visible, and the paper was positioned between the observer and the picture so that the back edge of the paper was $2 \mathrm{in}(508 \mathrm{~cm})$ below and $2 \mathrm{in} \mathrm{in} \mathrm{front} \mathrm{of} \mathrm{the} \mathrm{picture} \mathrm{Observers}$ were given unlimited time to position the discs on the paper, but on most trials they completed the task in less than a minute

\section{Results}

The averaged results for all 5 observers, labeled layout condition in Figure 2, show both the locations of points A, B, and C for viewing angles of $20^{\circ}, 90^{\circ}$, and $160^{\circ}$ and the actual layout of the dowels The data for all 5 observers were combined by scaling side BC to the same length for all observers, and in Figure 2 this side is set equal to side BC for the actual layout ${ }^{1}$ The data for the other viewing angles are not included, but the triangles for the omitted views fall in an orderly sequence between the $20^{\circ}$ and $160^{\circ}$ triangles. Comparison of the averaged, scaled triangles with the actual spatial layout indicates that at all viewing angles observers underestımate the distance between $A$ and $B$, and this result is also apparent in the raw unscaled data for each of the individual observers This underestımation of the distance be-

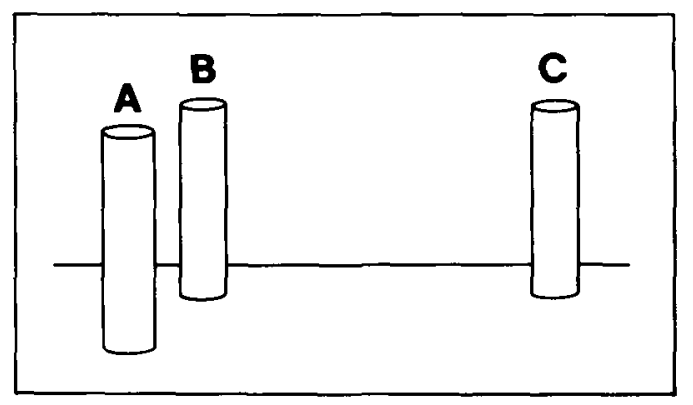

Figure 1 Line drawing traced from the photograph that served as the stımulus for Experıments 1 and 2 (For the actual stimulus the letters were omitted and the dowels had horizontal black and white stripes to clearly differentiate them from the background The actual aspect ratio of the stımulus was $4 \frac{1}{2} \times 31 / 2$ )
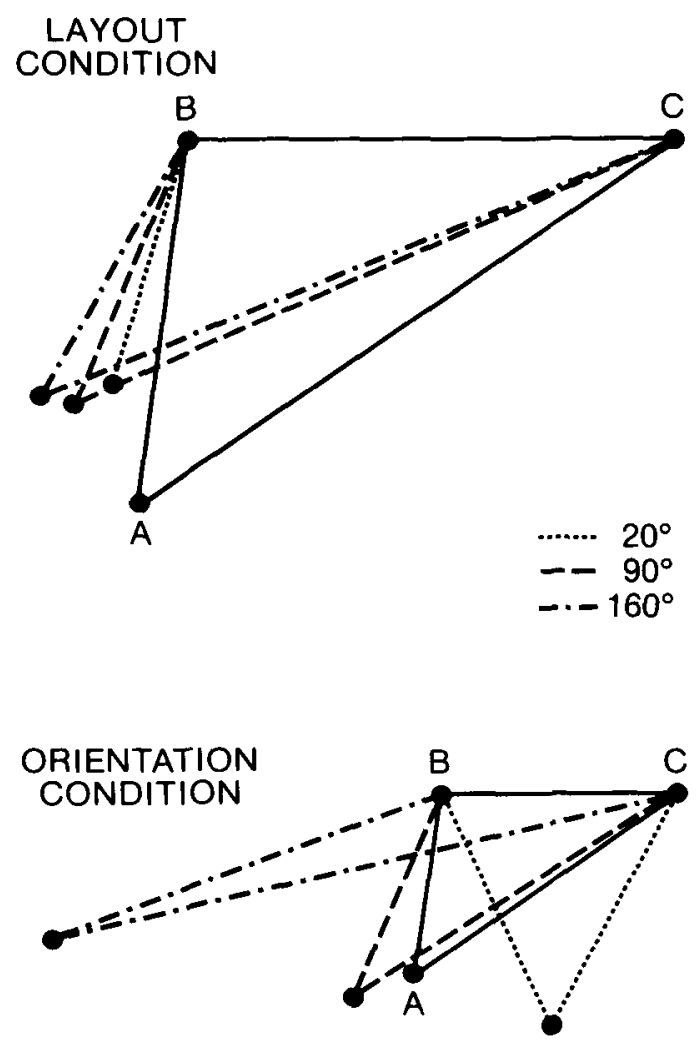

Figure 2 Results for Experıment I (layout condition) and Experıment 2 (orientation condition) (The points marked A, B, and C represent the actual layout of the dowels shown in Figure $I$ as seen from above ) Layout condition Triangles represent the average layouts produced by 5 observers in response to the stımulus in Figure 1 when viewed at angles of $20^{\circ}, 90^{\circ}$, and $160^{\circ}$ Orientation condition Triangles calculated from the results in Figure 3 (Average of judgments made by 5 observers Standard error of the mean for Experiment 1 ranged from a low of $\pm 11^{\circ}$ for angle $\mathrm{C}$ to a high of $\pm 55^{\circ}$ for angle $B$ Variability for Experiment 2 is indicated in Figure 3 )

tween objects extended in depth has also been reported for three-dimensional objects in an environmental settıng (Wagner, 1985).

The most important result for our purposes is that observers" perception of spatial layout changes only slightly as viewng angle is varied between $20^{\circ}$ and $160^{\circ}$. The same result also occurs for each individual observer. ${ }^{2}$

\footnotetext{
'Side BC was used as the "anchor" in companng the perceived layouts to the actual layout because of side BC's lack of extension in depth and its orientation parallel to the horizon line and to the lower edge of the picture These properties enabled our observers to judge the separation and orientation of dowels $B$ and $C$ more accurately than for pairs $\mathrm{AB}$ and $\mathrm{AC}$, which were extended in depth (cf Wagner, 1985)

${ }^{2}$ The relative constancy of the spatial layout judgments shown in Figure 2 is not an artifact of the procedure, in which observers knew they were seeing the same picture throughout the experiment This was shown by eliciting layout judgments from a different group of observers using the following procedure. The observers viewed pictures of four different arrangements of the three dowels, the picture in Figure 1 and three additional pictures These pictures were presented in random or-
} 


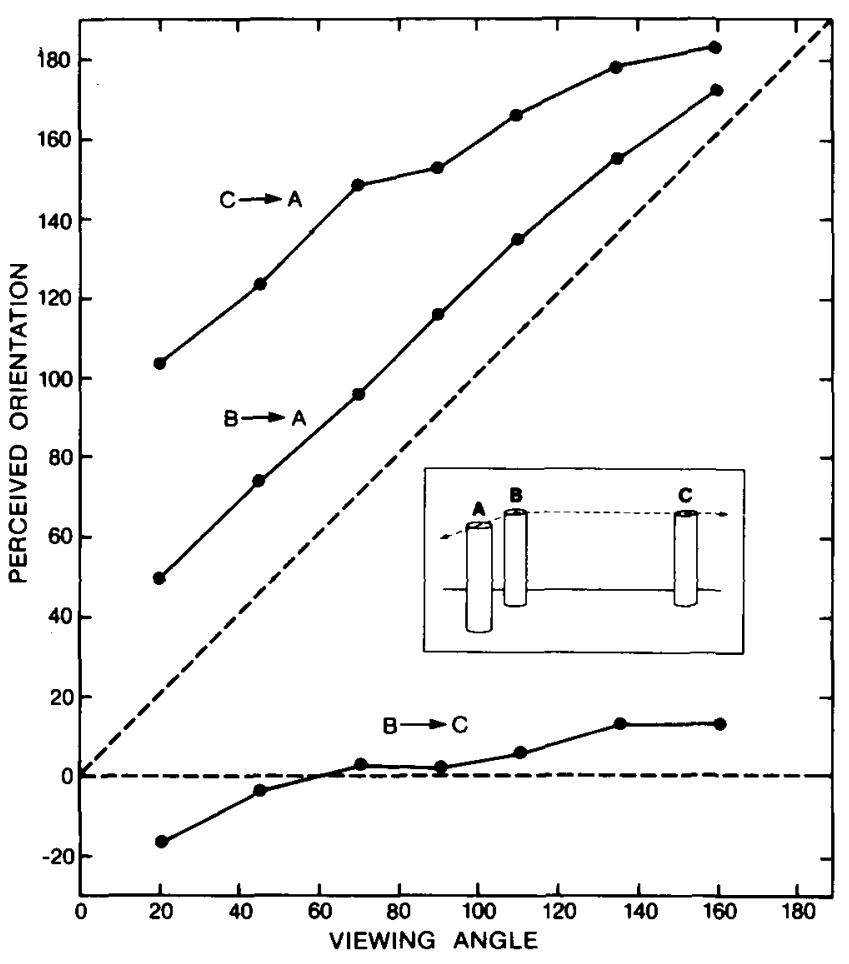

Figure 3 Perceived onentations of the directions defined by pairs of rod stımulı (see insert) at viewing angles of $20^{\circ}, 40^{\circ}, 70^{\circ}, 90^{\circ}, 110^{\circ}, 130^{\circ}$, and $160^{\circ}$ (Each point is the average data from 5 observers who made two judgments at each viewing angles Standard error of the mean ranged from a high of $\pm 6.3^{\circ}$ for pair $B C$ to a low of $\pm 32^{\circ}$ for pair $B A$ )

\section{Experiment 2}

In this experiment, the effect of changes in viewing angle on the perception of the orientations of pairs of dowels relative to the observer is demonstrated by having observers judge the direction defined by extending imagnary lines between pairs of the dowels in Figure 1, as shown in the inset to Figure 3.

\section{Method}

Observers The observers were the same as for Experiment 1

Stımulus The stımulus was the same as for Experiment 1

Procedure Observers viewed the picture from the same angles as in Experıment 1 , and at each angle they set a pointer to match the directoons defined by extending imaginary lines from dowels $B$ to $C$, from $B$ to $A$, and from $C$ to $A$ The pointer was mounted just below the picture and rotated around the picture's axus of rotation Percelved orientation is defined as the angle between the setting of the pointer and the picture plane If the pointer is set so that it is parallel to the picture. pointing to the right, the perceived orientation is $0^{\circ}$; if the pointer is set perpendicu-

der at viewing angles of $20^{\circ}, 90^{\circ}$, and $160^{\circ}$, with some observers seing the $20^{\circ}$ view first, some seeing the 90 -degree view first, and some seeing the $160^{\circ}$ new first The display was masked from vew as pictures and viewing angles were changed Under these conditions, the relative constancy of percerved spatial layout shown in Figure 2 was replicated, both for the picture in Figure 1 and for the additional pictures lar to the picture, the perceived orientation is $90^{\circ}$, and if the pointer is set so that it is parallel to the picture, pointung to the left, the perceived orientation is $180^{\circ}$ (See Figure 3 of Goldstein, 1979, for further details)

\section{Results}

Figure 3 shows the relation for perceived onentation versus viewing angle for the direction defined by each of the pairs of dowels. These results demonstrate the differentral rotation effect described by Goldstein (1979). That 1 s, objects that define directions close to perpendicular to the picture plane (such as the line between dowels $B$ and $A$ ) change their perceived onentation more with changes in vewing angle than do objects that define directions that are more parallel to the picture plane (such as the line between $\mathrm{B}$ and $\mathrm{C}$ ). For the change in viewing angle of $140^{\circ}$ that occurred between the $20^{\circ}$ and $160^{\circ}$ vewing angles, the perceived onentation of $B \rightarrow A$ changes $123^{\circ}, \mathrm{C} \rightarrow$ A changes $79^{\circ}$, and $B \rightarrow C$ changes $29^{\circ}$.

To facilitate comparison of the results for Experiments 1 and 2 , the percerved orientations for each par of dowels was used to determine triangular layouts at each viewing angle This layout was constructed by first setting side BC to an identical size for all observers and then determining the angle between $B \rightarrow A$ and $B \rightarrow C$ from the perceived orientations of $B \rightarrow A$ and $B \rightarrow$ $C$ This angle, marked $B$ in the plot labeled ortentation condition in Figure 2, defines the directrons of sides $\mathrm{BA}$ and $\mathrm{BC}$ of the triangle. The direction of side $\mathrm{CA}$ was determined by calculating angle $C$ from the perceived orientations of $B \rightarrow C$ and $C \rightarrow$ A, thereby completing the triangle.

The triangles calculated using this procedure are shown for viewing angles of $20^{\circ}, 90^{\circ}$, and $160^{\circ}$. As for the layout condition, the data for the other viewing angles have been omitted for clarity, with the omitted triangles falling in an orderly sequence between the $20^{\circ}$ and $160^{\circ}$ triangles. In marked contrast to the relative constancy of the triangles in the layout condition, these triangles differ greatly from each other. When the picture is viewed straight on (viewing angle $=90^{\circ}$ ), the resulting triangle almost matches the actual layout of the dowels, but the triangles from more extreme viewing angles are distorted compared with the actual layout and differ greatly from one another. (The closest match to the actual layout is acheeved for the $70^{\circ}$ vewing angle [not shown], which results in a triangle that almost exactly matches the actual layout of the dowels )

\section{Discussion of Experiments 1 and 2}

A comparison of the results for Experıments 1 and 2 illustrates large differences in how spatial layout and perceived orientation are perceived in a picture viewed at an angle. The perception of spatial layout changes only slightly with changes in viewing angle, whereas the perception of onentation relative to the observer changes dramatically with changes in viewing angle.

The large differences in the triangles derived from the orientation task for different viewng angles are a manifestation of the differential rotation effect-that is, the fact that the change in perceived orientation with changes in viewing angle is different for objects with differing orientations Pictured objects that point directly out of a picture, such as Uncle Sam's finger in the 


\section{MODEL}

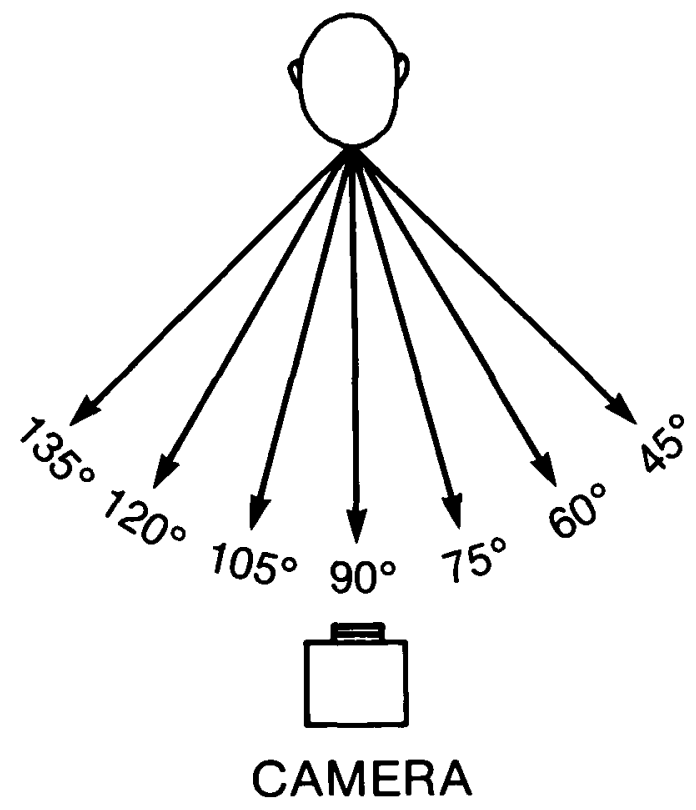

Figure 4 Top view of setup for producing photographs of faces with different gaze directions and head onentations (In Experiment 3 the model sat facing the camera [head orientation $=90^{\circ}$ ] and, keeping her head stationary, looked at targets located at $45^{\circ}, 60^{\circ}, 75^{\circ}, 90^{\circ}, 105^{\circ}, 120^{\circ}$, and $135^{\circ}$ These directions specify the gaze direction of the resultıng photographs In Experiment 4, the same procedure was used, but, in addition, pictures were taken with the model's head turned to face the $45^{\circ}, 60^{\circ}$, and $75^{\circ}$ targets These directions specify the head orientations of the resulting photographs)

"Uncle Sam Wants You" recrustıng poster, appear to "rotate" so that they maintain a constant direction relative to the observer, pointing directly at the observer no matter where the observer is positioned relative to the picture. Objects that point to the side, however, rotate less, and do not, therefore, maintann a constant direction relative to a moving observer.

Why does the differential rotation effect occur? One possibility is that the amount of rotation is a function of the perspective information that causes us to perceive an object in depth. $\mathrm{Ob}$ jects that appear to extend forward and back into the picture, like Uncle Sam's finger or the line connectung dowels A and B (considering this pair of dowels as an "object"), rotate more, whereas objects that have less extension in depth, like the pair of dowels $B$ and $C$, rotate less The results of Experıments 3 and 4 show that the differential rotation effect cannot be explanned in these terms, because it also occurs for pictures of human faces, stimuli in which information about direction is provided, not by perspective information but by the position of the pupil in the eye socket

\section{Experiment 3}

In this experiment, the effect of changes in viewng angle on a portrait's perceived gaze direction is measured for a portrait that appears to be looking directly at the observer and for six portraits that appear to be lookıng to the left or nght of the observer

\section{Method}

Observers Seven observers included the author, 3 undergraduates who were doing other projects in the laboratory, and 3 undergraduates who were recruited from the introductory psychology subject pool at the University of Pittsburgh

Stımul The stımulı were seven photographs of a human face, which were obtauned by photographing a female model Seven different gaze directions were created by photographing the model, positioned 45 in (1143 cm) from the film plane of a $4 \times 5-1 n(127 \mathrm{~cm})$ vew camera with Polarord back, and taking photographs as she looked at each of seven targets The $90^{\circ}$ target was the lens of the camera, and the other targets were discs located at eye level positioned every $15^{\circ}$ as shown in Figure 4 For gaze directions of $45^{\circ}, 60^{\circ}$, and $75^{\circ}$ the model looked to the left of the camera, and for gaze directions of $105^{\circ}, 120^{\circ}$, and $135^{\circ}$ the model looked to the right of the camera Line drawngs made by tracing photographs for the $45^{\circ}, 90^{\circ}$, and $135^{\circ}$ gaze directions are shown in Figure 5 The length of the model's head was 9 in $(2286 \mathrm{~cm})$, and the image of her face in the photograph was 3 in $(762 \mathrm{~cm})$ high

Procedure The procedure was identical to that described by Goldstein (1979) except that photographs of faces were used as stımulı instead of line drawings of rods Obser vers viewed each portrait monocularly from different viewing angles and at each viewing angle judged the perceived gaze direction by setting a pornter, which was mounted just below the picture and which rotated around the picture's axis of rotation, to match the direction the portrait appeared to be lookıng Vtewing angle is defined in the same way as for Experiment 1 Percelved gaze direction is equivalent to perceived ortentation as defined in Experiment 2

\section{Results}

Figure 6 is a plot of perceived gaze direction versus viewing angle, with gaze direction as the parameter. The curve for the $90^{\circ}$ gaze direction (pupils centered) falls along the diagonal, which indicates that perceived gaze direction always matches the observer's viewing angle This confirms the common observation that when a straight-on face is looking directly at an observer, its eyes will "rotate" to follow the observer so that they appear to be looking directly at the observer no matter where he or she is relative to the picture As the viewing angle is changed from $20^{\circ}$ to $160^{\circ}$, the perceived gaze direction for the $90^{\circ}$ face changes from $22^{\circ}$ to $159^{\circ}$, a total rotation of $137^{\circ}$. The faces with other gaze directions, however, rotate less for the same change in viewing angle For example, as the viewing angle

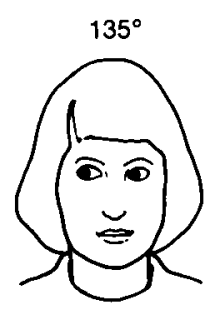

A

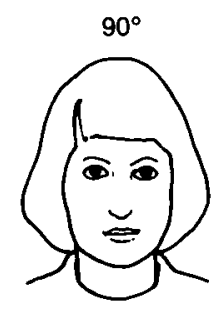

B

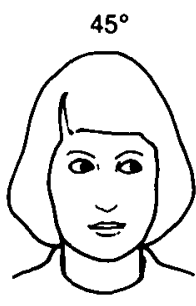

C
Figure 5 Drawings of three of the face stımulı used in Experıment 3 (These line drawings were traced from the photographs that were used as stumuli Numbers under each face indicate gaze direction ) 


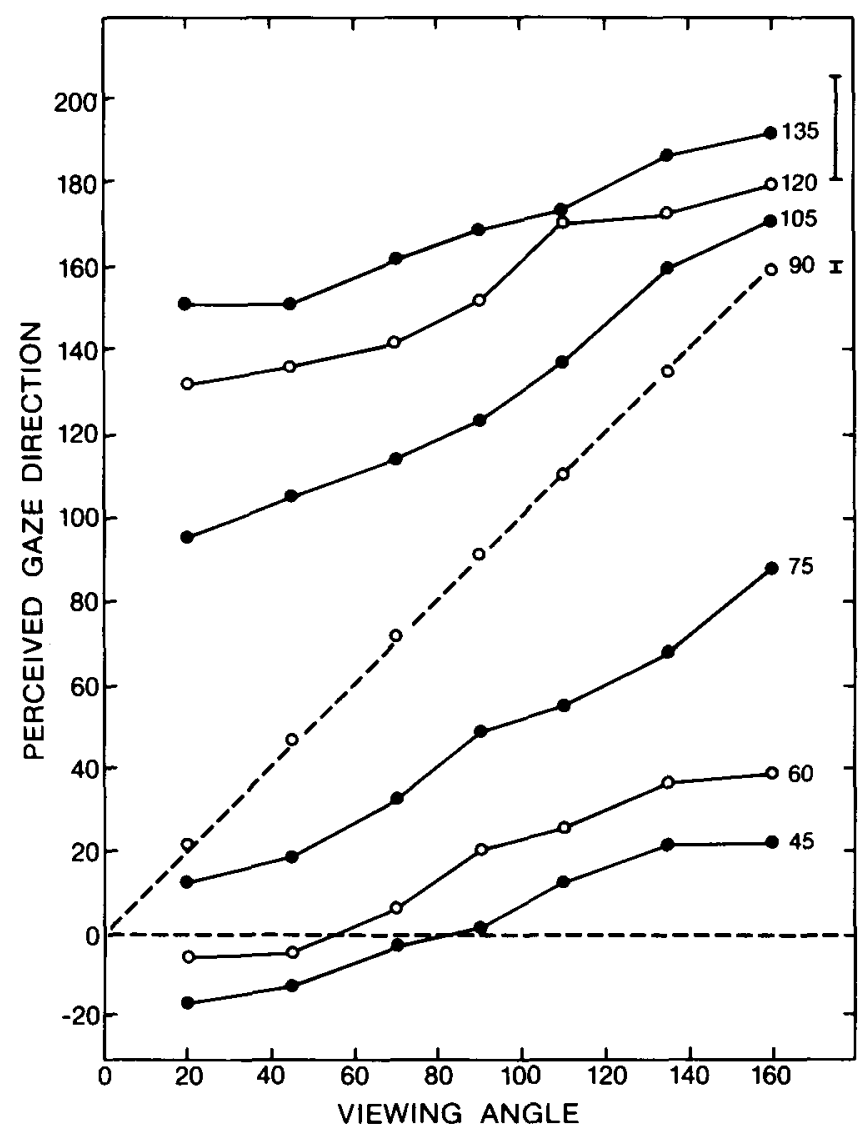

Figure 6 Perceived gaze direction for each of the face stimul at viewing angles of $20^{\circ}, 40^{\circ}, 70^{\circ}, 90^{\circ}, 110^{\circ}, 130^{\circ}$, and $160^{\circ}$ (The number to the right of each curve is the gaze direction of the face Each point is the average data from 7 observers who made two judgments at each viewing angle Plus or minus one standard error of the mean for the $135^{\circ}$ curve [maximum variability] and the $90^{\circ}$ curve [minimum variability] is indcated by the bars opposite the curves)

Is changed from $20^{\circ}$ to $160^{\circ}$, the perceived gaze direction for the face with a $45^{\circ}$ gaze direction changes from $-16^{\circ}$ (the negatrve direction indicating that the face appears to be looking in back of the right side of the picture) to $22^{\circ}$, a total rotation of only $38^{\circ}$.

The relation between total rotation and gaze direction is plotted in Figure 7 This result, which is qualitatively similar to the result shown in Figure 5 of Goldstein (1979), shows that the differential rotation effect occurs for pictures of faces.

\section{Experiment 4}

This experiment is identical to Experiment 3 except that gaze direction was measured for both a straight-on face and for three additional faces with heads turned in a counterclockwise direction

\section{Method}

Observers Four observers included the author and 3 undergraduates who were doing other projects in the laboratory
Stımult The stimuli in this experiment were photographs of a model's face produced as described in Experiment 3 except that in addition to photographing the model as she was directly facing the camera, photographs were also taken of three addituonal head ortentations A total of four different head orientations were, therefore, used For the $90^{\circ}$ head orientation, shown as a line drawing on the left of Figure 8 , the model directly faced the camera For the $75^{\circ}, 60^{\circ}$, and $45^{\circ}$ degree head onentations, the model's face was rotated in a counterclockwise direction by having her face the $75^{\circ}, 60^{\circ}$, and $45^{\circ}$ degree targets (see Figure 4) The line drawnig on the right of Fugure 8 shows a head orientaition of $60^{\circ}$.

Gaze direction is determined, as in Experiment 1, in terms of the targets at which the model was looking. Thus, turning the head affects the position of the pupils, but the gaze direction indicates where the model is lookung, independent of head orrentation That is, no matter what the head orientation, a $90^{\circ}$ gaze direction indicates that the model is looking directly at the camera This is illustrated by the $60^{\circ}$ head orientation of Figure 8 The gaze direction of $90^{\circ}$ results in the pupils' being positioned off-center, but the model appears to be looking at the camera

Procedure The procedure was identical to the procedure for Experi-

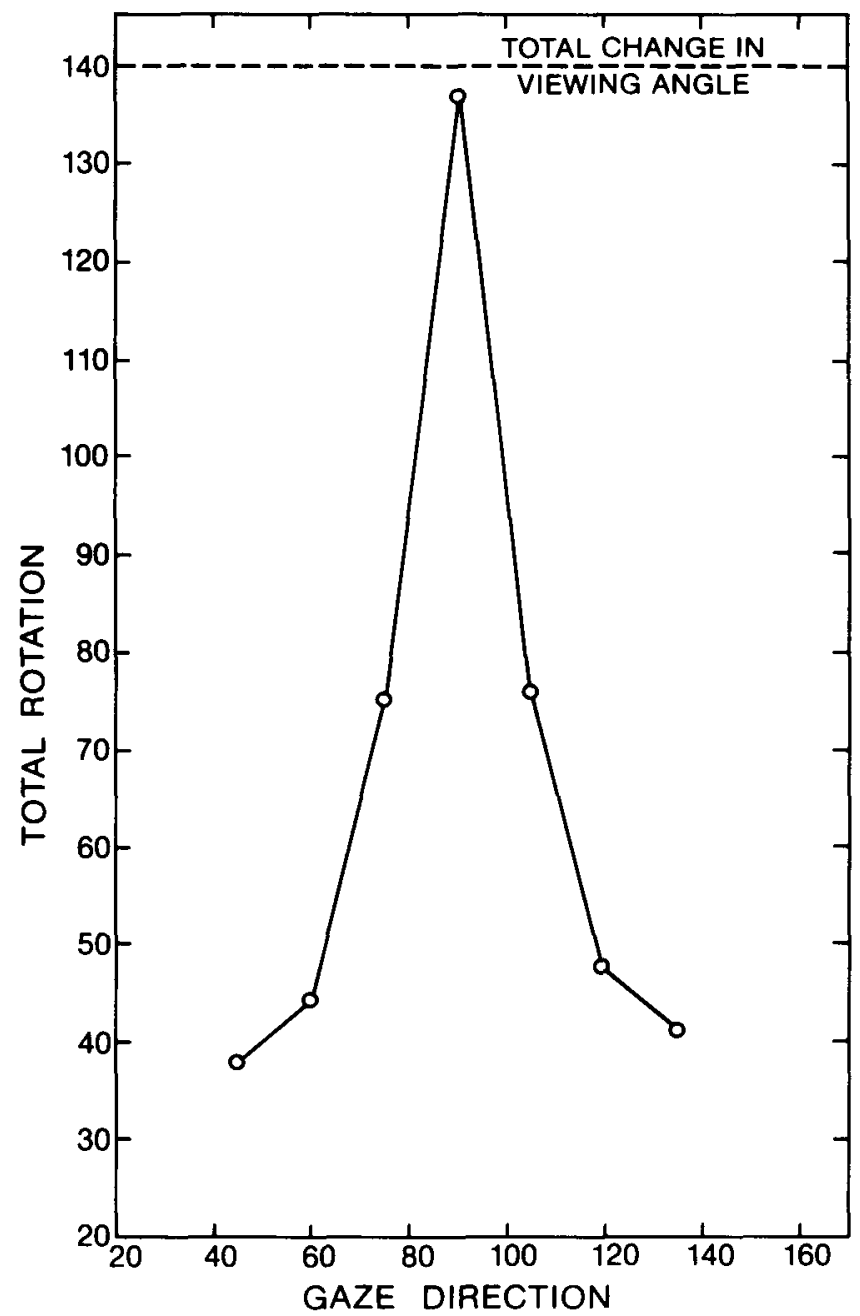

Figure 7 Relation between the total change in percelved gaze direction that occurs when the viewing angle changes from $20^{\circ}$ to $160^{\circ}$ and gaze direction, derived from the data in Figure 6 

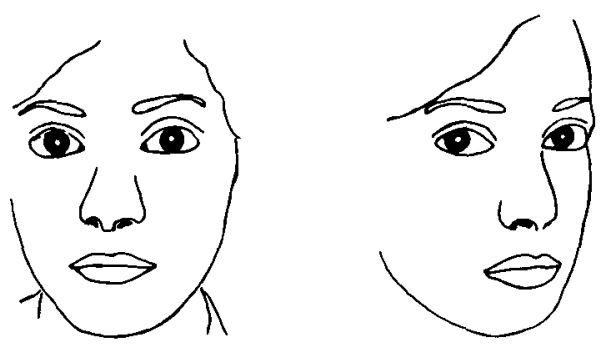

Figure 8 Line drawings traced from photographs of two of the stımuli used for Experıment 2 Left $90^{\circ}$ head onentation, $90^{\circ}$ gaze direction Right $60^{\circ}$ head orientation, $90^{\circ}$ gaze direction

ment 3 except each of the faces was presented with a small prece of white paper covering the right eye of the photograph This was done because Noll (1976) has shown that when a model's head is turned and she is looking at an observer, the model's farther eye (in our case, the model's left eye) appears to be looking at the observer, while her nearer eye appears to be looking away from the observer Reflecting Noll's result, our observers reported that it was more difficuit to estımate where the faces were lookıng when both of the photograph's eyes were visible than when just one eye was visible.

\section{Results}

The results of this experiment are similar to the results of Experiment 3 When the head is turned to the side, rotation

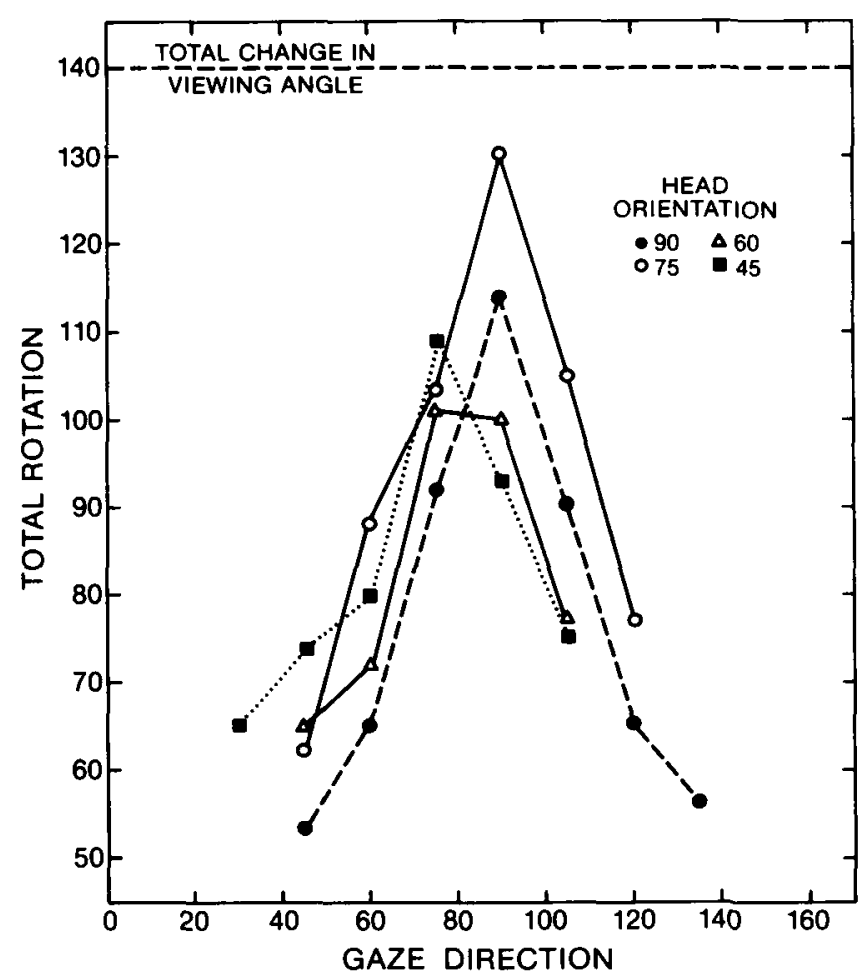

Figure 9 Relation between the total change in percerved gaze direction that occurs when the vewing angle changes from $20^{\circ}$ to $160^{\circ}$ and gaze direction, for four different head orientations

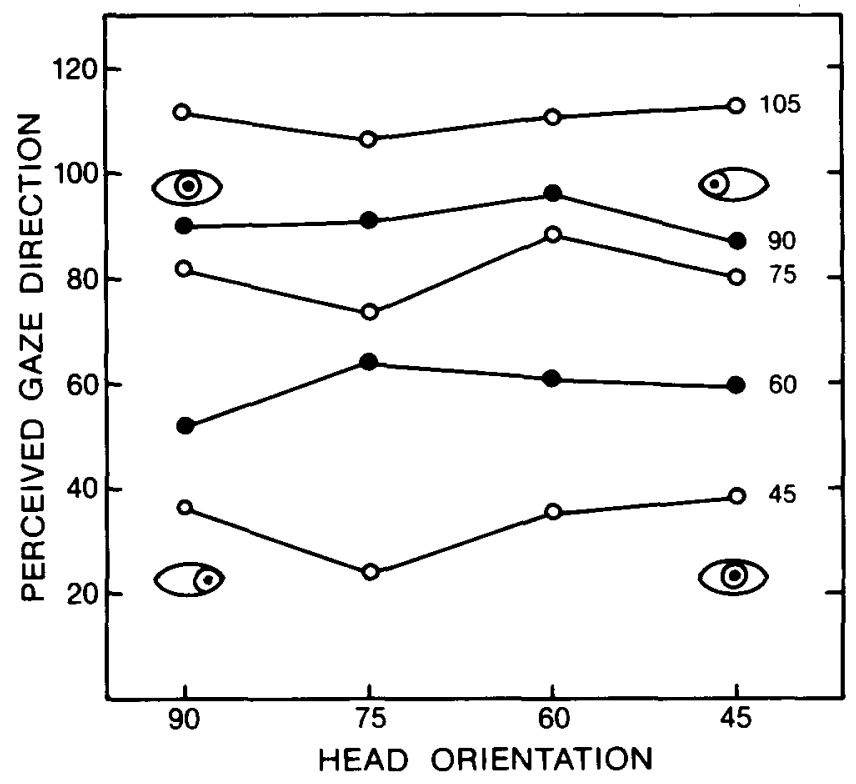

Figure 10 Perceived gaze direction versus head onentation, for five different gaze directions. (Gaze direction is indicated by the numbers to the right of each curve Eyes show pupil positions for $90^{\circ}$ and $45^{\circ}$ head orientations with gaze directions of $45^{\circ}$ and $90^{\circ}$ )

occurs for all gaze directions, but rotation is greater when the model is lookung either toward the observer ( $90^{\circ}$ gaze direction) or just to the observer's right $\left(70^{\circ}\right.$ gaze direction). This result is summarized by the plots of total rotation versus gaze direction in Figure 9. The total rotation for this face is less than for the one used in Experiment 3, but the qualitative result-a peaked function for the relation between total rotation and gaze directuon-1s similar.

In Figure 10, perceived gaze direction is plotted versus head orientation, with gaze direction as parameter, for a viewing angle of $90^{\circ}$. The data are plotted in this way to show that the perceived gaze direction is relatively constant for a given gaze direction, independent of head onentation A similar result occurs for the other viewing angles

\section{Discussion of Experiments 3 and 4}

Previous investigations of gaze direction have measured an observer's ability to Judge where live models (Anstıs, Mayhew, \& Morley, 1969, Cline, 1967; Gibson \& Pick, 1963) or television portraits (Anstıs et al , 1969) are lookung. The present exper1ments present the first measurements of the relation between a photographed face's direction of gaze and the degree of "following" or "rotation" that occurs with changes in viewing angle. The major finding of these experiments is that the differentual rotation effect previously observed for representations of threedimensional objects such as pointing fingers, cylinders, or objects in scenes, all of which are extended in depth, also occurs for pictures of faces, stimuli in which information for direction is indicated by the position of the pupil in the eye socket. Thus, whatever mechanism is responsible for this following effect, it does not depend on the extension of pictured objects in depth 
Rather, the extent of rotation appears to depend on the directoon of extension out of the picture, no matter whether this direction is determined by three-dimensional objects that are extended in pictorial space or by objects that are essentially flat like portraits. The $90^{\circ}$ face provides the most obvious example of direction being determined by two-dimensional information because the front view of the face has little depth and direction being determined by the left-right position of the pupils in the eye sockets. ${ }^{3}$

The present results also confirm Noll's (1976) finding that in faces turned to the side, observers take head turn into account in judging perceived gaze direction But most important for our purposes is the finding that the differential rotation effect occurs for all head orientations. The differential rotation effect is, therefore, a general phenomenon that occurs not only for representations of three-dimensional objects extended in pictorial space but also for portraits that drrectly face the observer and for portraits in which the head is seen at an angle.

It has been shown that extension of an object in space is not necessary for the differential rotation effect, but the question remains What controls the portrat's rotation? The answer that is usually given for portraits like the one in Figure 5b, which always appears to be lookıng at the observer, has been stated by Gombrich (1972) as follows

In a paintıng, an object with a pronounced aspect such as a foreshortened gunbarrel, a pointıng finger, or human eye will contınue to show the same aspect from whatever side we look at the picture If these objects were not panted, but real, any move on our part would, of course, show them from a different side and reveal a different aspect, since we fall to produce this change, we instinctively assume that the object is still pointing at us and must therefore have moved (p 142)

Thus, for the portrait that is lookung straight ahead, the pupils always appear centered, and these centered pupıls provide infor- (a)

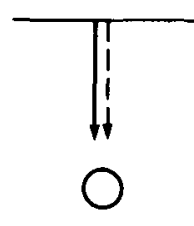

(c)

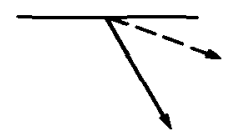

O (b)

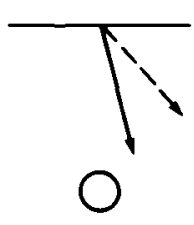

(d)
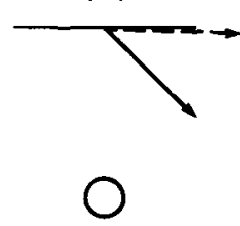

Figure II Gaze direction (sold line) and perceived gaze direction (dashed line) for an observer at 0 viewing a face with head onentation $=90^{\circ}$ Panel a Gaze direction $=90^{\circ}$; percetved gaze direction $=91^{\circ}$ Panel b Gaze direction $=75^{\circ}$, perceivel gaze direction $=49^{\circ}$ Panel $\mathrm{c}$ Gaze direction $=60^{\circ}$, perceived gaze direction $=21^{\circ}$ Panel d Gaze direction $=45^{\circ}$, perceived gaze direction $=2^{\circ}$ (Based on the data in Figure 3)
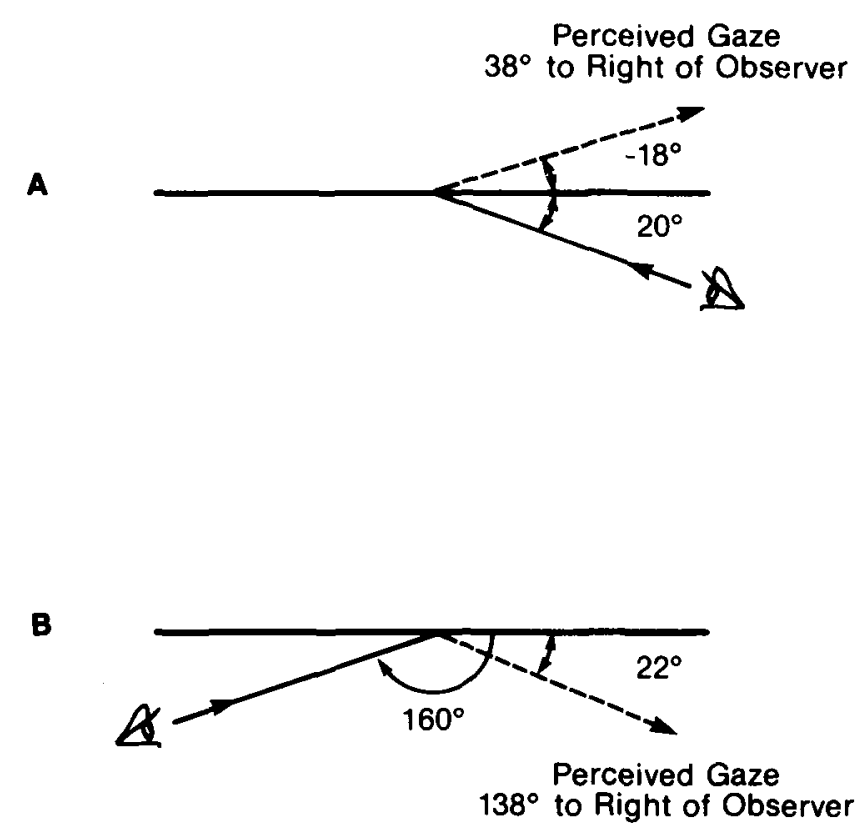

Figure 12 Perceived gaze direction (dashed line) for an obser ver viewng a portrait with a gaze direction of $45^{\circ}$ at vewing angles of (Panel A) $20^{\circ}$ and (Panel B) $160^{\circ}$ (The picture plane is indicated by the horizontal line Based on the data in Figure 6)

mation that signals "being looked at" However, the situation for portraits that look to the side is somewhat more complex.

One of the complexities of portraits that look to the side is the fact that the portrait's angle of gaze is overestimated This result, which was originally reported by Anstus et al. (1969), is llustrated in Figure 11 for the case of an observer, at $O$, who is newing the picture straight on (viewing angle $=90^{\circ}$ ). In Figure 11a, when the portrait is lookung directly at the camera (gaze angle $=90^{\circ}$ ), the gaze direction (solid line) and perceived gaze direction (dashed lıne) match. However, when the portrait is looking off to the side as in Figure $1 \mathrm{lb}$ (gaze angle $=75^{\circ}$ ), Figure $11 \mathrm{c}$ (gaze angle $=60^{\circ}$ ), and Figure 11d (gaze angle $=45^{\circ}$ ), the percelved gaze direction is far to the right of the actual direction of the model's gaze. A similar result occurs for the rod stimulı used by Goldstein (1979)

Further complicating the situation for portraits looking to the side is that although the pupil's "aspect" is perceived as relatively constant at different viewing angles, this constant aspect does not signal a constant gaze direction relative to the ohserver, as Gombrich hypothesized for portraits that always look drectly at the observer. We can appreciate this by referring to Figure 12, which shows the percelved gaze direction relative to the observer for a portrait with a gaze direction of $45^{\circ}$ when viewed from two angles. When the portratt is viewed from the far right (viewing angle $=20^{\circ}$ ), the portratt's gaze is perceived to be $38^{\circ}$ to the right of the observer, but when the portratt is

\footnotetext{
${ }^{3}$ Although the position of the pupils in the eye socket can be considered two-dimensional information, the observer's judgment of direction is based on the knowledge that the position of the pupl indicates the degree of rotation of the three-dimensional eyeball
} 
vewed from the far left (vewing angle $=160^{\circ}$ ), the portrant's gaze is perceived to be $138^{\circ}$ to the right of the observer Analogous results occur for all oblique gaze directions

This change in the direction of a portrait's gaze relative to the observer, which is a manifestation of the differential rotation effect, means that Gombrich's explanation for the rotation effect holds for objects that are pointing directly at the observer but not for objects that are pointing off to the side The problem with Gombrich's explanation, however, may be not that it is wrong but simply that it is incomplete. It is true that the position of the eyeball (or, more correctly, the position of the eyeball in combination with the orientation of the head) does signal a specific direction of gaze relative to the observer. However, the position of the eyeball also signals a specific direction of gaze relative to the left and right sides of the picture Thus, a portrant such as the one in Figure 5c is looking both to the right of the observer and toward the right side of the picture, and as the observer moves to the left, the portrait contunues to look to the observer's right, but is constrained from following the observer fully because it also contains information that indicates that it is looking toward the nght side of the picture. Portraits that appear to be looking toward the left or night side of the picture appear to be constrained from fully rotating to follow an observer to the extent that they are percelved to be lookıng to the side Portraits that look more toward the front appear to be constrained less, so that the $90^{\circ}$ portrait (Figure 5b), which is free of such constraints, is free to totally follow the observer no matter where he or she is in relation to the picture.

If the information about the direction of gaze relative to the left or right side of the picture, does, in fact, decrease the following effect, then elimination of this information should increase the amount of following. This hypothesis was tested in Exper1ment 5 by making the picture plane invisible. To accomplish this, the experiment was run in the dark, with the stımulus made visible by using back-lit transparencies of line drawngs, which appeared in the dark as white line drawings floating in space

\section{Experiment 5}

\section{Method}

Observers Four undergraduates who were working on other projects in the laboratory served as observers

Stımuh Face stımuli were not used in this experiment because our observers found judging the direction of a portrait's gaze to be very difficult when a back-lluminated hne drawng of the portrat was vewed in the dark The reason for this difficulty is that when the portrait is viewed in the dark, the projectuve changes that occur at oblique viewing angles become much more obvious than when the portrait is viewed in the light, and the portrait therefore appears distorted at these vewing angles Thus, judging the direction of a portrait's gaze, a dificult task when the portrait is viewed in the light, becomes more difficult and increasingly vanable when the portrait is vewed in the dark. Therefore, instead of faces, a line drawing of two vertical cylinders similar to those used in Experiments 1 and 2 was used as the stımulus (Figure 13) A black-on-white line drawing of the cylinders was used when the stımulı were newed in the light, and a back-lit negative prepared from this line drawing was used when the stimuli were vewed in the dark The observer's task was to set the pointer, which was made visible in the dark by coatung it with fluorescent paint, to match the direction defined by an
Imaginary line connectıng the left and nght cylınders (See Figure 13) Although projectuve deformations are also obvious when this stımulus is viewed obliquely in the dark, judging the direction defined by the two cylinders is easier and less variable than judgng the direction of gaze

Procedure The procedure was similar to that in Experiments 3 and 4 Observers viewed the picture monocularly from different viewng angles and judged the direction defined by the two cylinders by setting the pointer mounted just below the picture plane This procedure was carned out in the light and in the dark, using the same procedure in both cases, except that in the dark the subjects closed their eyes as the picture plane was being rotated to a new position so they would not see the projective changes of the stimulus that occur during this rotation

\section{Results}

The open circles in Figure 13 shows the relation between viewing angle and perceived orientation for the stimuli when vewed in the light. A total change in veewing angle of $150^{\circ}$ results in a total change in perceived orientation of only $60^{\circ}$, a result simular to that observed for any stumulus that is oriented oblıquely to the picture plane (Goldstein, 1979; Experiment 2 in this article) and simular to the result for the portraits looking to the side (Figure 6). The filled circles show the same relation for the stimuli when viewed in the dark. When viewed in the dark, these stımul rotate $113^{\circ}$, almost twice as much as when viewed in the light, although still less than the rotation that would be expected if the change in perceived orientation matched the change in viewing angle (dashed line).

\section{Discussion}

The results of Experiment 5 show that eliminating perception of the picture plane increases the amount of rotation for pic-

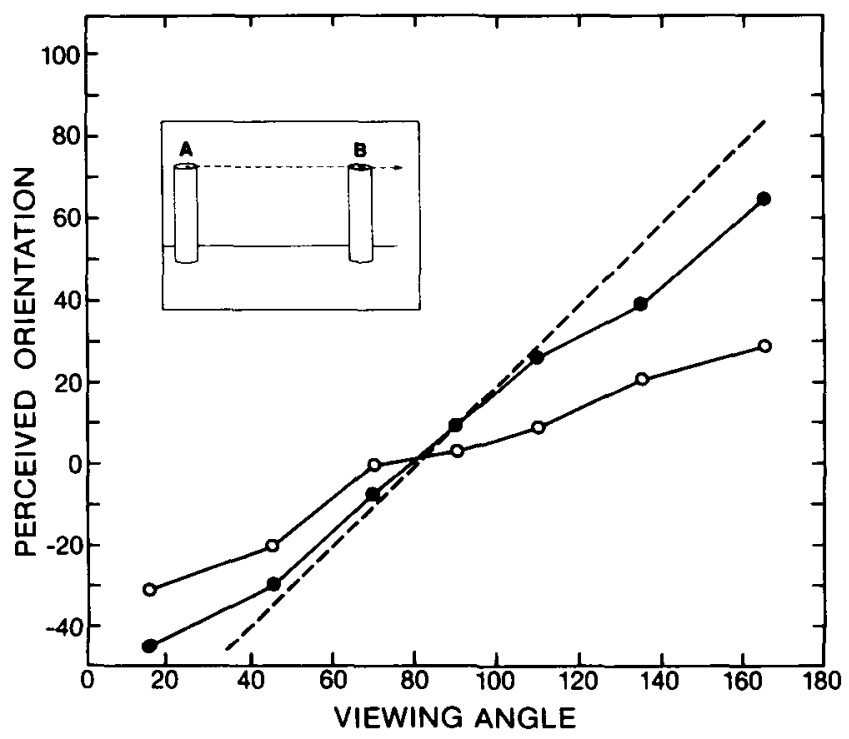

Figure 13 Perceived orientation versus viewing angle for the stimul shown in the inset when viewed in the light (open circles) and in the dark (filled circles) (The dashed line indicates the result that would occur if the change in perceived orientation matched the change in viewing angle Each point is the average data of 4 observers who made two judgments at each viewing angle Standard errors of the mean for the light condition ranged from a high of $\pm 115^{\circ}$ for the $15^{\circ}$ viewing angle to $\pm 45^{\circ}$ for the $90^{\circ}$ viewng angle, and for the dark condition from $\pm 136^{\circ}$ for the $165^{\circ}$ viewing angle to $\pm 46^{\circ}$ for the $90^{\circ}$ viewng angle ) 
tured objects that define a direction oblique to the picture plane. Objects that define a direction that is perpendicular to the picture plane are not affected by this manipulation because they already rotate maximally; that is, for a change in the viewIng angle of $150^{\circ}$, these objects rotate $150^{\circ}$ both in the light and in the dark.

The increase in rotation that occurs for obliquely onented objects when viewed in the dark does not, however, result in the maximum possible rotation, as indicated by the fact that the data diverge from the dashed line in Figure 13. The reason for this fallure to rotate fully may be that even though viewing the stımulı in the dark elımınates perception of the picture plane, projective information contained in the image of the back-lit stımulı provides some cues to the picture's orientation.

Even though maximal rotation was not obtained in the dark, the results of Experiment 5 are consistent with the idea that a complete explanation of the rotation effect must take into account the fact that the constant aspect characteristic of pictured abjects means that a picture contains information that simultaneously signals two different directions: (a) a direction relative to the observer and (b) a direction relative to the left or right side of the picture. These two directions are not necessarily the same and, in fact, become quite different when the observer vews the picture from, say, the far left when the pictured object defines a direction far to the right This difference appears to be the reason that obliquely oriented objects rotate less than would be expected if only their aspect relative to the observer were controllıng their percerved onentation.

One remaining question is why the rotation of stimuli that are pointing straight out of the picture is not inhibited by the fact that they contain information indicating that they define a direction perpendicular to the picture plane Perhaps the fact that these stımulı are perceived to point directly at the observer causes observers to focus their attention on this aspect of the stimulus information and to ignore the conflicting information indicatıng their direction relative to the picture plane.

\section{General Discussion}

It has often been sad that pictures define a dual reality - the reality of the three-dimensional space depicted in the picture and the reality of the two-dimensional surface on which the picture exists. The experiments reported here show that this property of pictures leads to another dual reality: Changing viewing angle has only a small effect on the perception of the layout of objects in pictorial space, but it has a large effect on the perception of the object's onentation relative to the observer

The lability of perceived orientation is most apparent for objects that define directions parallel, or nearly parallel, to the picture plane In contrast to objects that define directions perpendicular to the picture plane and that rotate so they constantly point at a moving observer, objects not directed perpendicularly to the picture plane rotate too little to maintain a constant orientation relative to the observer and, therefore, take on different orientations as the observer changes position relative to the picture.

The results of Experiments 3, 4, and 5 support the idea that the reduced rotation of these objects is due, not to the objects' lack of extension in pictorial space, but is rather due to the fact

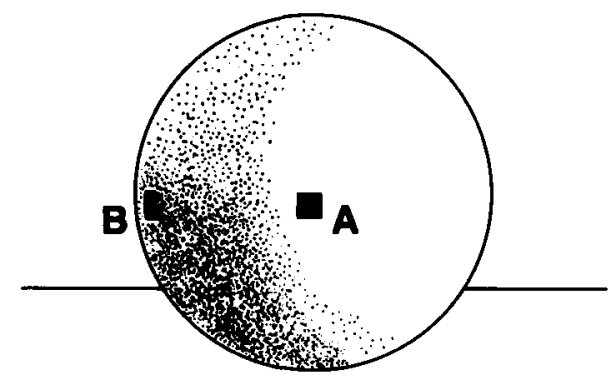

Figure 14 A line drawing of the sphere stımulus. (The actual stımulus was a photograph Observers judged the perceived orientation of the sphere at points A and $B$. The actual stumulus showed only one of the points, either point $A$ [actual onentation $=90^{\circ}$ ] or point $B$ [actual orientation $=150^{\circ}$, and did not include the letters )

that the direction defined by these objects is compared with the left-to-right axis of the picture plane. According to this idea, such an object is constrained from fully rotating because no matter where the observer is, this object must contunue to point etther toward the left or the right side of the picture.

The picture plane's constraining effect on rotation means that perceived orientation is not determined solely by the geometrical information provided by the picture. This conclusion 1s supported by the fact that when viewing a pictured object from certain angles, the perceived orientations of parts of the object are inconsistent with the object's geometry. For example, consider the sphere in Figure 14. When 3 observers vewed a photograph of this sphere from an angle of $20^{\circ}$ (far to the right of the picture), their average judgment of the orientations of the sphere at points A and B was $25^{\circ}$ and $153^{\circ}$, respectively. This $128^{\circ}$ difference in orientation cannot, however, be predicted from the sphere's geometry. The maxımum separation that two visible points can have on the circumference of either a sphere or the ellipsoid which the sphere becomes when viewed at an angle of $20^{\circ}$, is $180^{\circ}$. The maxımum separation between point A, which is in the center of the sphere/ellipsoid, and another visible point, is $90^{\circ}$ The observed difference of $128^{\circ}$ between the perceived orientations of points A and B far exceeds both the theoretical limit of $90^{\circ}$ and the points' actual separation of $60^{\circ}$. The percerved onentation of these points on the sphere cannot, therefore, be solely determıned by the picture's geometry.

This sphere experiment replicates, with a different stımulus, the results of Experiment 3, in which observers made judgments of gaze direction for different positions of the pupil in the eye socket. Consider, for example, our observers' judgments of perceived gaze direction for the $90^{\circ}$ and $135^{\circ}$ stımuli when viewed from an angle of $20^{\circ}$ (Figure 6). These two stımuli represent a difference in the position of the eyeball of only $45^{\circ}$, but the difference in perceived gaze direction is $128^{\circ}$. (At a viewing angle of $20^{\circ}$, the percerved gaze directions of the $135^{\circ}$ and $90^{\circ}$ stımulı are $151^{\circ}$ and $22^{\circ}$, respectively.) Percerved gaze directıons, or orientations, relative to an observer, therefore bear litthe resemblance to the actual physical onientations of objects in the picture.

In contrast to the noncorrespondence between judgments of perceived orientatıons relative to the observer and the physical orientations of objects, our observers' judgments of spatial lay- 
Table 1

Properties of Three Attributes of Pictures

\begin{tabular}{|c|c|c|c|}
\hline Attribute & Example & $\begin{array}{l}\text { Is Attribute Sensitive to Viewing } \\
\text { at an Angle? }\end{array}$ & Is 3-D Illusion Necessary? \\
\hline Spatıal layout & $\begin{array}{l}\text { The house is in the middle of the } \\
\text { field and is perpendicular to } \\
\text { the road }\end{array}$ & $\begin{array}{l}\text { Slightly Reproduction of layout stays } \\
\text { relatively constant with changes in } \\
\text { viewing angle (Figure 2) }\end{array}$ & $\begin{array}{l}\text { Yes Space, or layout, as defined } \\
\text { here, implies three-dimen- } \\
\text { stonality }\end{array}$ \\
\hline Perceived orientation & $\begin{array}{l}\text { If extended out of the picture, the } \\
\text { house is pointing over my right } \\
\text { shoulder }\end{array}$ & $\begin{array}{l}\text { Yes "Differential rotation effect" } \\
\text { (Figures } 2 \& 3 \text { ) }\end{array}$ & $\begin{array}{l}\text { No Occurs for representations of } \\
\text { both 3-D objects and faces (but } \\
\text { object must define a direction } \\
\text { which can be extended out of } \\
\text { the picture) }\end{array}$ \\
\hline Projection & $\begin{array}{l}\text { The picture of the house appears } \\
\text { narrow when viewed at an } \\
\text { angle }\end{array}$ & $\begin{array}{l}\text { Yes Perception is directly related to the } \\
\text { changes in projection that occur with } \\
\text { changes in viewing angle Identical } \\
\text { pictures viewed from different angles } \\
\text { appear different }\end{array}$ & $\begin{array}{l}\text { No Occurs for representations of } \\
\text { both 2-D and 3-D objects }\end{array}$ \\
\hline
\end{tabular}

out do bear some resemblance to the actual layout of objects in the picture. Although this correspondence between judged spatial layout and actual spatial layout is by no means perfect in the present experiments (cf. Figure 2), the spatial layout of a picture of three dowels is reproduced with greater accuracy if depth information is enhanced by placing the dowels on a textured ground and photographing them from a higher viewpoint (Goldstein, 1986)

It is clear from the results of the experiments reported in this article that the pictorial attributes of perceived orientation and spatıal layout have different properties and must, therefore, be distınguished from one another in any research on the perception of pictures The importance of making this distinction is nowhere more important than in considering one of the problems addressed at the beginning of this article-whether pictures appear distorted when viewed at an angle.

Clearly, one attribute (perceived orientation) changes drastically with changes in viewing angle, whereas another (spatial layout) changes only slightly, and we can also add a third attr1bute to this list: the perception of the picture's projection on the retina This attribute of pictures does change with changes in viewing angle, although these changes are usually unnoticed by most observers. The fact that changes in projective information go unnoticed has been noted by many authors. For example, Haber (1980) seems to be referring to projective information when the states that "One can move around while lookıng at any scene, without the scene appeanng to change, even though each successive retınal pattern undergoes massive changes" (p. 19)

The fact that these projective changes are not noticed does not mean, however, that it is not possible to perceive them. One reason that people have difficulty in perceiving projective changes has been proposed by Rosinski and Farber (1980), who suggest that "observers cannot judge that a scene is distorted unless they know what it is supposed to look like. This information is not avallable at the incorrect viewing point" (p. 150)

According to this idea, an observer could perceive these distortions if two views of the scene from different station points were avalable for comparison, and this can easily be accom- plished by obtaining two identical copies of a picture and positoning them at right angles so that one can be viewed straight on, and the other at an angle When this is done, the distortions in the picture viewed at an angle become obvious, with objects in this picture appearing compressed compared with objects in the other picture

The projective changes that occur when viewing pictures at an angle may pass unnoticed not only because of the absence of a comparison new from the correct station point but also because of the stability of the picture's spatial layout This possible linkage between the two attributes of picture is implied (although not explicitly stated) by Rosinskı and Farber's (1980) statement that "We perceive a pictorial representation of space veridically, even when the geometric projection to the eye is greatly distorted. Moreover, pictures apparently look the same regardless of the viewing point" (p 149). The first sentence of this quotation refers to the constancy of spatial layout, which has been empirically demonstrated in Experiment 1, whereas the second sentence appears to refer to the difficulty in noticing projective changes Perhaps the constancy of spatial layout directs attention away from distortions in projective information that cause pictures viewed at different angles to appear different. If this is so, we would predict that changes in appearance caused by changes in projective information would be more easly detected in pictures that contain little depth information, as in abstract art or drawings of two-dimensional geometrical figures Although this comparison remains to be made, Thouless' (1931) classic experıments on "phenomonal regression to the real object" clearly shows that observers perceive a circle at an angle as an ellipse Thus, Thouless' results, although usually cited to dllustrate our fallure to perceive an object's projective shape, also provide evidence that pictures of two-dimensional geometrical objects do look different when viewed at an angle.

Some of the properties of the three attributes of pictures discussed here - spatial layout, orientation relative to the observer, and projective information-are summarized in Table 1 The examples in this table refer to how a person might describe a perspective picture of a house that is depicted as perpendicular to a road 
The importance of distınguishing among these three different attributes of pictures cannot be overemphasized, because a falure to make this distinction can lead to confusion, especially when discussing how pictures are perceived when viewed at an angle. For example, consider the following excerpts from Pirenne's (1970) discussion of the effects of viewing a picture at an angle

With reference to the viewing of portrats at an angle, he states.

When as is most often the case, ordmary pictures are seen binocularly from a position different from the center of projection, they do not as a rule give a noticeably deformed view of the scene represented (p 97)

With reference to architectural drawings viewed at an angle, he states:

For most observers deformations of this kund are netther obvious or striking Many people only notice such deformations when their attention has been drawn to them, and then only after some practice, even if they use one eye only (p 157)

And this is Pirenne's suggestion of a possible mechanism to explain the difficulty we have in perceiving distortions in pictures viewed at an angle.

In general, therefore, the fact that many find it difficult to see the deformations theoretically predicted for a spectator who is not at the correct position, must be explaned by an intuitive process of psychological compensation which is based both on the spectator's awareness of the surface of the picture, and on his preconceived Ideas regarding the components of the scene presented

It is the existence of these processes which must largely explain that pictures in perspective can be used as widely as they are as representations of complicated scenes or objects, even for purely practical purposes (p 162)

The problem is that in each of these excerpts it is unclear to which attributes Pirenne is referring. His reference to the absence of a "noticeably deformed view" of portraits in the first excerpt seems to refer to projective information. However, Pirenne's references to architectural drawings in the second excerpt and to "pictures in perspective" and "complicated scenes or objects" in the third excerpt leave open the possibility that these statements refer to an observer's perception of spatial layout

Pirenne's lack of explicitness makes it difficult for us to know exactly which attributes of pictures he is concerned with (projective shape? spatial layout? orientation relative to the observer?), and it also limits his ability to analyze these properties. Consider, for example, the issue of deformation. A theme throughout Pirenne's discussion is that pictures are deformed when viewed at an angle, but that this deformation is hard to notice. If Pirenne is concerned solely with projective deformation, then he is on solid ground. But one wonders whether Pirenne's statement that deformations are difficult to notice is based solely on his observations of the projective attribute of pictures. Is it possible that he is influenced by the fact that deformations of spatal layout do not occur? Is he lumping together the two phenomena of (a) projective deformations that are difficult to perceive and (b) spatial deformations that do not occur and then attempting to study them? The answers to these questions are not obvious from Pirenne's discussion, but if he is combining these two attributes, confusion is bound to be the result For example, Pirenne's idea of a compensation mechanism based on our perception of the surface of the picture may hold for perception of projective changes but may be less important for perception of spatial layout, which might be more profitably analyzed in terms of identifying information for spatial layout that remains invariant with changes in viewing angle

The confusion that can occur by ignoring the fact that different attributes of pictures have different properties, especially with reference to how these properties change with changes in viewing angle, argues that it is important to distunguish among these attributes. Although some of the mechanisms responsible for the properties of the various attributes remain to be determined, distınguishing among them is the first step in uncovering these mechanisms, and making these distinctions will, at the least, help us to know what we are talkıng about.

\section{References}

Anstis, S M , Mayhew, J W, \& Morley, T (1969) The perception of where a face or television 'portrait' is looking American Joumal of Psychology, 82, 474-489

Cline, M.G (1967) The perception of where a person is looking American Journal of Psychology, 80, 41-50

Gibson, J. J , \& Pick, A D (1963) Perception of another person's looking behavior American Journal of Psychology, 76, 386-394

Goldsteın, E. B (1979) Rotation of objects in pictures viewed at an angle Evidence for different properties of two types of pictorial space Journal of Expermental Psychology Human Perception and Performance, 5. 78-87

Goldsteın, E B (1986) [Recovering three-dimensional layout from two-dimensional representations ] Unpublished observations.

Gombrich, E H (1972) The "what and the how" Perspective representation and the phenomenal world In R Rudner \& I. Scheffler, (Eds.), Logic and art New York Bobbs-Merrill

Haber, R. (1980) Perceiving space from pictures A theoretical analysis In M A Hagen (Ed), The perception of ptctures (Vol 1, pp 3-31) New York Academic Press

Noll, A. M (1976) The effects of visible eye and head turn on the perception of being looked at American Joumal of Psychology, 89, 631644

Prrenne, M H (1970) Optics, painting and photography Cambridge, England Cambridge University Press

Rosinsk1, R R , \& Farber, J (1980) Compensation for viewing point in the perception of pictured space In M A Hagen (Ed.), The percep tion of pictures (Vol. 1, pp 137-176). New York. Academic Press

Thouless, R H (1931) Phenomenal regression to the real object British Journal of Psychology, 21, 339-359

Wagner, M (1985) The metric of visual space Perception \& Psychophysics, 38, 483-495

Recerved November 1, 1986

Accepted November 28, 1986 . 